\title{
The African Dream for Quality Higher Education
}

\author{
Ahmed Legrouri
}

\section{Introduction}

Education is well established as a leading means for building broad-based social welfare, promoting economic development and eradicating poverty. Most governments and international development agencies have, for many years, argued for a sequential development of schooling, giving priority to primary and then to secondary education before moving on to higher education. The World Education Forum: Education for All (Dakar, Senegal in 2000) advocated for primary education as a lone driver for development. In 2015, the United Nations recognised the role of HE in advancing the 2030 sustainable development agenda. HE is mentioned among the 17 Sustainable Development Goals (SDGs) in target 4.3 and forms an important part of other goals (See Higher Education and Research for Sustainable Development (HESD) global portal, International Association of Universities).

The relevance and the contribution of $\mathrm{HE}$ and scientific research to economic, social and political development is well recognised in today's world. The increase in the relevance and the quality of these two sectors has become a priority in the strategic agendas of most nations, and especially in developing countries. In this knowledge economy and society, HE is entrusted with the practical mission of creating knowledge that offers solutions to the critical problems facing society. In 2009, the World Bank (2009) argued for the need of higher-order skills and expertise in Sub-Saharan Africa in order to achieve sustainable growth and to be successful in global knowledge-driven markets.

In contrast to traditional education, 21st century HE institutions (HEIs) are required to provide new skills and abilities in this fast-advancing digital era. Several studies have reported that, because of technological advances in all fields, some jobs will disappear, and others will emerge in the near future, and employment

\footnotetext{
A. Legrouri $(\bowtie)$

International University of Grand-Bassam, Grand-Bassam, Côte d'Ivoire e-mail: legrouri@gmail.com 
would therefore require new professional skills and competencies (OECD 2019). Therefore, HEIs should offer practical and dynamic classes and put the emphasis on long-lasting soft skills (critical thinking, leadership, entrepreneurship, communication, languages, innovation, agility, etc.), in addition to the competencies of specific disciplines (computer science, mathematics, finance, economics, political science, sociology, etc.). Ehlers and Kellermann (2019) categorised future skills into 16 skill profiles subdivided into three dimensions, namely (1) individual development skills, (2) individual object-related skills and (3) individual organisation-related skills. Lifelong learning and permanent refreshment are necessary to protect HE graduates from unemployment in this rapidly changing era (Hodgson 2013).

It is within this African and international context that several initiatives have been launched in the continent to experiment new HE models and paradigms. In this paper, the dynamics of HE in Africa are discussed. Given the difference in this area between North and Sub-Saharan Africa, two countries are chosen as examples: Côte d'Ivoire and Morocco. Success stories and challenges facing these two countries are reviewed.

\section{The African Context}

Africa is a huge continent. With over 30 million $\mathrm{km}^{2}$, it could house within its contours China, USA, India, Japan and a very large part of Europe. It is endowed with rich and diverse natural resources. In addition, the continent has by far the world's youngest population, with a median age of 18 years, compared to 42 for Europe, 35 for North America and 31 for Asia and Latin America. Almost $41 \%$ of its population is under 15 -years-old, while only $3 \%$ is more than 65 years old (World Economic Forum 2020).

Africa has the highest rate of population growth. The population of sub-Saharan Africa, estimated to be a billion, is expected to double by 2050. At the same time, the working-age population is expected to increase from 705 million in 2018 to almost 1 billion by 2030 (African Development Bank 2019). This rapid growth would represent enormous opportunities for Africa and make it an important continent in the world economy if the youth is equipped with the right skills and given the right prospects. Otherwise, this will be a major threat as unemployment and underemployment of youth is a major challenge, which is enhanced by urban expansion in most African countries.

It is worth noting that African countries differ significantly, and it is difficult to generalise characteristics and trends in such a large and diverse continent. However, there are some common features and challenges, particularly in different regions. Regarding the HE sector, three countries or groups of countries appear to relate to each other: South Africa, Sub-Saharan Africa and North Africa.

Today, with all its assets, Africa is facing a variety of complex challenges as it attempts to eradicate poverty and build broad-based, social and economic development. One way to mitigate these challenges is to deploy relevant and dynamic 
strategies to create a critical mass of highly educated and skilled people. Therefore, there is a pressing need to improve the educational systems in most African countries, which are lagging behind all the other world regions. A successful transition from educational institutions to the labour market is a key factor to mitigate some of the challenges. Unfortunately, African tertiary education is under-developed, with only $16 \%$ of the relevant age group having access to this sector when the global average stands at about $48 \%$. Additionally, women are underrepresented in higher education, particularly in science and technology (S\&T).

As home to the world's oldest universities, Al Karawiyin in Morocco (859 AD) and Al-Azhar in Egypt (970 AD), Africa is aware of the benefits of HE, and for some time now, HE is recognised as a key sector in African development (Teferra and Altbach 2004). However, HEIs in many African countries are relatively few in number, but projects are underway to change that and also open HE to more females and to students from low-income areas.

In regard to quality, not a single African university features in the rankings of the world's best 100 academic institutions (Shanghai, Times Higher Education, QS, Webometrics). Only six universities appear among the top 500 in the Shanghai ranking (South Africa: 5, Egypt: 1). The number of all African countries listed in this ranking is equal to that of the Netherlands. In addition to South Africa and Egypt, Nigeria appears among the top 500 in the Times Higher Education ranking with two institutions.

In terms of research, Africa produced 58,824 (2.3\%) science and engineering articles in peer-reviewed journals out of the world's production of 2,555,959 in 2018 (National Science Foundation 2020). This is a little higher than the production of Spain. South Africa and Egypt share $43 \%$ of the African output, while the five North African countries produced $50 \%$. This is due to lack of funding for research, facilities and research-experienced faculty in most African HEIs. Another issue is that subSaharan Africa depends greatly on international collaboration for its research output. In 2015, South Africa produced $52 \%$ of its research papers with foreign co-authors (Ekrem 2020).

In the current era of knowledge and intelligence, developments in all areas are intertwined and growing fast, through innovation. Therefore, HE needs to adapt and adopt more entrepreneurial and innovative pedagogical approaches, research and development programmes as well as engage more with socio-professional actors. The governance model should incorporate strategic planning approaches, with SMART key performance indicators, leadership in the culture of change, continuous improvement through quality assurance and accreditation, and social responsibility. Such an innovative and creative model will also ensure the necessary academic integrity.

Apart from South Africa, most of the countries in Sub-Saharan Africa and North Africa regions present several common features. Therefore, two representative countries were chosen as examples: Côte d'Ivoire and Morocco. The HE systems in these two countries, which are based on the French model, have undergone several reforms since independence. The public HEIs may be subdivided into three main components: (1) open-access HEIs that give access to any student with a high school diploma, leading to massification of these institutions, (2) regulated-access HEIs (engineering, 
business, medical, architecture, ...) that are very selective and offer better employment conditions and job prospects to their students, (3) vocational training schools. Some of the regulated-access HEIs are under the supervision of ministries other than the ministry of Higher Education and Scientific Research.

In an attempt to increase the competitiveness of their HE systems, Côte d'Ivoire (in 2009) and Morocco (in 2003) adopted the three-cycle system (3-year Licence/ Bachelor, 2-year Master, 3-year Doctorate) of the Bologna process, created by the European Higher Education Area in 1999. In an attempt to meet society's expectations and labour market needs as well as to enhance the skills set of students, the Moroccan government decided to move away from the 3-year Licence/Bachelor. Starting 2020-2021, the 4-year Bachelor will include, in addition to the speciality courses, modules of foreign languages and four sets of soft skills (study, life, civic, professional skills).

In this globalised world, many non-English-speaking countries are increasing the number of English-taught degree programmes, either partially or entirely. This type of programmes has grown notably during the 21 st century worldwide, including in francophone Africa. Côte d'Ivoire and Morocco have established two independent, US-style and English language-medium universities; namely, the International University of Grand-Bassam (IUGB 2005) and Al Akhawayn University in Ifrane (AUI 1995), respectively. AUI and IUGB, as liberal-arts institutions, have adopted the use of technology and innovative approaches in their teaching and learning systems as well as in their other activities. In order to ensure quality, both institutions are adopting best practices in HE and working with accreditation institutions in the USA. AUI received programme accreditations and institutional accreditation in 2018 from the New England Commission of Higher Education.

In 2017-2018, Côte d'Ivoire counted 219,368 students (41\% female) in 36 universities and 240 specialty schools. Aware of the role of the development of human capital as a major key for national development, the government initiated a ten-year education and training development plan (2016-2025), which includes HE\&SR. Several actions were undertaken to improve the HE system, including the creation of a Joint Commission (private sector/HE), the extension and rehabilitation of existing universities and the construction of six new institutions in different regions, the promotion of quality assurance and accreditation as well as the culture of evaluation. However, despite all these efforts, the sector still faces several challenges, including mobilisation of financial resources, management of human resources, massification of public universities, internal performance (student failure and drop-out) and external performance (level of graduates' professional integration).

In 2019-2020, Morocco counted 1,009,678 students (49\% female) in 23 universities. The marked disinterest of students for science and the unemployment rate of graduates in open-access HEIs, among other reasons, led to the reform of the 3-year Licence/Bachelor. The 01-00 law (2000) brought some strengths to the HE system, such as institutional autonomy. HEIs establish their internal quality assurance system based on on-going self-assessment. Two national evaluation and quality assurance agencies are in charge of evaluating HEIs, training programmes, scientific research, ... Several challenges are still to be addressed in the near future, with the two major 
ones being linguistic inconsistency and the inadequacy of training adapted to labour market needs, mainly from open-access HEIs.

It is worth noting that, in both Côte d'Ivoire and Morocco, the employability of the graduates of some specialty schools, like engineering, medical, business, etc., is good. Unfortunately, a good number of these graduates opt to serve the developedcountries' job markets.

\section{Conclusion}

Although Africa has demonstrated significant efforts to improve its HE systems, most of its diverse societies have not yet reached the desired level to compete within knowledge economies. HE in the continent is seriously affected by the low level of countries' economies. Students from low-income families are generally tempted to enter informal job markets instead of seeking more knowledge, competencies and skills needed for high-level positions. In Africa, unemployment rates tend to be higher among university graduates than the uneducated or less educated youth.

There are several success stories to learn from within the continent. The last decade witnessed the emergence of certain HEIs that adopted active, entrepreneurial and interdisciplinary approaches and offered more meaningful and articulated learning environments. These institutions also understood the role of internationalisation and joined networking initiatives, such as the International Association of Universities, for collaboration, knowledge exchange and advocacy of best practices in HE.

However, most of the public HEIs in Africa are finding it difficult to embrace innovative educational approaches, mainly because of lack of resources and overwhelming student enrolment. Governments and all stakeholders are aware of the challenges and are working on improving their education and training offers.

21 st century students are digital and need dynamic and practical classes and opportunities to develop both their technical skills, through regular interaction with socio-professional environments, and their interpersonal skills, through co-curricular activities and international experience.

\section{References}

African Development Bank (2019). African Economic Outlook 2019, Retrieved from: https:// www.afdb.org/fileadmin/uploads/afdb/Documents/Publications/2019AEO/AEO\$_\$2019-EN. pdf (1.06.2020)

Ehlers, U.-D., \& Kellermann, S.A. (2019). Future Skills: The Future of Learning and Higher education. Karlsruhe, Germany: Results of the International Future Skills Delphi Survey.

Ekrem J. (2020). South Africa by the numbers: An overview of its $S \& T$ performance, Brussels, Belgium: Science Business Publishing International, Retrieved from: https://sciencebusiness. net/international-news/south-africa-numbers-overview-its-st-performance. (1.06.2020) 
Hodgson A., Editor (2013). Policies, Politics and the Future of Lifelong Learning. Abingdon-onThames, UK: Routledge.

National Science Foundation (2020). National Center for Science and Engineering Statistics, National Science Foundation, Retrieved from: https://ncses.nsf.gov/pubs/nsb20206/publicationoutput-by-region-country-or-economy (1.06.2020)

OECD (2019), The Future of Work. OECD Employment Outlook 2019, Retrieved from: https:// www.oecd.org/employment/Employment-Outlook-2019-Highlight-EN.pdf (26.07.2020)

Teferra D., \& Altbach P.G. (2004). African higher education: Challenges for the 21 st century, Higher Education, 47: 21-50.

World Bank (2009). Accelerating Catch-up: Tertiary Education for Growth in Sub-Saharan Africa. Directions in Development, Retrieved from: https://openknowledge.worldbank.org/ handle/10986/2589 (26.07.2020)

World Economic Forum (2020). Mapped: The median age of the population on every continent, Retrieved from: https://www.weforum.org (26.05.2020)

Ahmed Legrouri is Provost \& VPAA, International University of Grand-Bassam, Côte d'Ivoire. He holds a BS, Rabat University, Morocco, a Doctorate, INP Toulouse, France, and a Ph.D., Glasgow University, UK. He was Professor at Marrakech University and Professor, Dean \& VPAA at Al Akhawayn University in Ifrane, Morocco. He supervised several doctoral theses and published more than eighty peer-reviewed articles. He is a member of several advisory committees and received several merit-based fellowships. He speaks Arabic, English, French and German.

Open Access This chapter is licensed under the terms of the Creative Commons Attribution 4.0 International License (http://creativecommons.org/licenses/by/4.0/), which permits use, sharing, adaptation, distribution and reproduction in any medium or format, as long as you give appropriate credit to the original author(s) and the source, provide a link to the Creative Commons license and indicate if changes were made.

The images or other third party material in this chapter are included in the chapter's Creative Commons license, unless indicated otherwise in a credit line to the material. If material is not included in the chapter's Creative Commons license and your intended use is not permitted by statutory regulation or exceeds the permitted use, you will need to obtain permission directly from the copyright holder.

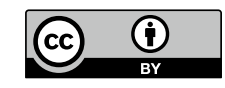

